\title{
Response to commentary re 'Majority of females with a life-long experience of CAH and parents do not consider females with CAH to be intersex'
}

\author{
Konrad M. Szymanski* \\ Benjamin Whittam \\ Richard C. Rink \\ Division of Pediatric Urology, Riley Hospital for Children at Indiana University Health, Indianapolis, \\ IN, USA
}

Two subpopulations appear to exist among women with $\mathrm{CAH}$ born with atypical genitalia. The majority and minority groups differ greatly in their viewpoints regarding identifying as intersex, being legally designated as intersex, and (as a soon to be published subsequent report from this study indicates) legislation banning early surgery. This provides only further support that these challenging decisions should be made thoughtfully and in a supportive multidisciplinary environment, not legislated with a "one size fits all" approach. These early treatment decisions remain an extremely complex issue that requires input from parents with the support of physicians, ethicists and mental health experts, all within the context of the patient and family's social situation. As healthcare providers, it is our duty to honestly share and distinguish what we know (data) and do not know (anecdotes) about controversies surrounding treatments.

This is the author's manuscript of the work published in final edited form as:

Szymanski, K. M., Whittam, B., \& Rink, R. C. (2021). Response to commentary re "Majority of females with a life-long experience of CAH and parents do not consider females with CAH to be intersex." Journal of Pediatric Urology, 17(2), 213. https://doi.org/10.1016/j.jpurol.2020.12.009 